\title{
Wanderers with Cognitive Impairment in Department of Veterans Affairs Nursing Home Care Units
}

\author{
Lawrence Schonfeld, PhD, * Bellinda King-Kallimanis, MS, * Lisa M. Brown, PhD, ${ }^{*}$ Darlene M. Davis, \\ RD, MHA, NHA, ${ }^{\dagger}$ William D. Kearns, PhD, ${ }^{*}$ Victor A. Molinari, PhD, ${ }^{*}$ Dennis H. Werner, MHA, ${ }^{\ddagger}$ \\ Elizabeth R. Beattie, PhD, RN, ${ }^{\mathcal{S}}$ and Audrey L. Nelson, PhD, $R N^{\ddagger}$
}

OBJECTIVES: To explore the extent of and factors associated with male nursing home residents who wander.

DESIGN: Cross-sectional design with secondary data analyses.

SETTING: One hundred thirty-four nursing home facilities operated by the Department of Veterans Affairs.

PARTICIPANTS: Fifteen thousand ninety-two nursing home residents with moderate or severe cognitive impairment admitted over a 4-year period.

MEASUREMENTS: Selected variables from the Minimum Data Set included ratings recorded at residents' admission to the nursing home (cognitive impairment, mood, behavior problems, activities of daily living, and wandering).

RESULTS: In this sample of residents with moderate or severe cognitive impairment, the proportion of wanderers was found to be $21 \%$. Wanderers were more likely to exhibit severe (vs moderate) cognitive impairment, socially inappropriate behavior, resistance to care, use of antipsychotic medication, independence in locomotion or ambulation, and dependence in activities of daily living related to basic hygiene. A sizable proportion of wanderers were found to be wheelchair users $(25 \%)$ or were wanderers with dual dementia and psychiatric diagnoses $(23 \%)$, characteristics that are not well documented in the literature.

CONCLUSION: These results support previous clinical understanding of wanderers to be those who are more likely to exhibit more-severe cognitive impairment. Based on a statistical model with variables generated from prior research findings, classification as a wanderer was found to be associated with other disruptive activity such as socially inappropriate behavior and resisting care. Two understudied populations of wanderers were documented: wheelchair

From the *Department of Aging and Mental Health, Louis de la Parte Florida Mental Health Institute, University of South Florida, Tampa, Florida;

${ }^{\dagger}$ Nursing Home Care Unit and ${ }^{\ddagger}$ Patient Safety Center of Inquiry, James A.

Haley Veterans Administration Medical Center, and ${ }^{\S}$ Office of Human

Research Compliance Review, University of Michigan, Ann Arbor, Michigan.

Address correspondence to Victor Molinari, PhD, ABPP, Department of Aging and Mental Health, Louis de la Parte Florida Mental Health Institute, University of South Florida, 13301 Bruce B. Downs Blvd., Tampa, FL. E-mail: vmolinari@fmhi.usf.edu

DOI: $10.1111 / \mathrm{j} .1532-5415.2007 .01135 . x$ wanderers and those with comorbid dementia and psychiatric diagnoses. Future longitudinal studies should examine predictors of wandering behavior, and further research should explore the understudied subpopulations of wheelchair and dual-diagnosis wanderers who emerged in this study. J Am Geriatr Soc 55:692-699, 2007.

Key words: wanderers; disruptive behavior; nursing home residents; Veterans Affairs

W andering of residents in nursing homes (NHs) is a challenging behavioral and safety problem. Adverse outcomes associated with wandering include accidents, weight loss, fatigue, sleep disturbance, abuse, getting lost, and untimely death. ${ }^{1-7}$ Wanderers are at risk of falling. ${ }^{8}$ Those who do fall are more likely to sustain fractures and are at high risk for hip fractures. ${ }^{9}$ Moreover, falls resulting from wandering contribute to premature mortality. ${ }^{1}$

Wanderers are more likely than others with dementia to be institutionalized. ${ }^{2,10-12}$ In NHs, wandering can lead to an increase in caregiver stress, stress in other residents because of intrusions into their rooms, and safety concerns that challenge care providers responsible for managing behavior problems. ${ }^{13,14}$

The purpose of this study was to investigate wandering behaviors in residents with moderate or severe cognitive impairment across Department of Veterans Affairs (VA) NHs nationally. This study's unique contribution was the use of a large, predominantly male sample, because prior studies have mostly focused on women across care settings. Furthermore, wandering behavior was explored in cognitively impaired residents with a variety of medical diagnoses, whereas previous studies have been largely limited to residents with dementia. The authors examined the Minimum Data Set (MDS) for the VA NHs over a 4-year period. Focusing on the assessments administered upon admission to the $\mathrm{NH}$, residents who were rated as wanderers were contrasted with residents rated as nonwanderers. A goal of this study was to formulate a statistical model to classify 
wanderers versus nonwanderers in residents with cognitive impairment using ratings recorded at admission to the $\mathrm{NH}$.

\section{BACKGROUND}

Although definitions vary, most researchers and healthcare providers agree that wandering refers to seemingly aimless or disoriented ambulation throughout a facility, often with observable patterns such as lapping, pacing, or random ambulation. ${ }^{15}$ Some wanderers have been perceived to have a purpose (e.g., escaping the facility), but the volitional, rational nature of wandering is difficult to measure. A review of this literature yields widely disparate prevalence rates for those with dementia, ranging from $11 \%$ to $63 \%$, reflecting varied samples of older cognitively impaired populations in diverse geriatric settings and use of different assessment instruments. ${ }^{16}$ Wandering appears more often in those diagnosed with Alzheimer's disease than those with vascular dementia. ${ }^{17}$ In contrast to nonwanderers, wanderers have greater cognitive impairment, with problems in recent and remote memory, orientation to time and place, and ability to respond appropriately to a given conversation topic. ${ }^{9}$

General variables associated with wandering include residential environment; various medical conditions; extraverted and agreeable personality traits; and prior history of high levels of social and leisure activities, stressful events, and "motoric" reactions to stress. ${ }^{18-20}$ More-specific variables associated with wandering include akathisia (a common side effect experienced by those on high levels of neuroleptic medications), exit seeking, modeling other residents' behaviors, or self-stimulation, in which wandering is but one stereotypical behavior. ${ }^{21}$ Negative behaviors associated with wandering include nonaggressive agitation, screaming and calling out, physical aggression, depression, and disturbed nighttime sleep. ${ }^{14,22}$

\section{SEX DIFFERENCES}

The relationship between wandering and sex is not clear. Most research on wandering has been conducted in community-based NHs, where female residents vastly outnumber men. One such study analyzed MDS data on first assessment in a cross-sectional sample of 28,367 residents with Alzheimer's disease across five states. Men more frequently exhibited wandering, abusiveness, and social impropriety than women. ${ }^{23}$

In another large, 2-year longitudinal study of wandering behavior, baseline and 3-month follow-up MDS assessments for 8,982 NH residents in Mississippi, Texas, and Vermont were conducted. ${ }^{24}$ Wandering occurred in $10.7 \%$ of cases at baseline and developed in an additional $2 \%$ of residents at follow-up, with no sex differences. Baseline prevalence of wandering was not significantly different between men and women (11\% vs $10.6 \%)$, although being male was identified as one of several predictors for eventually developing wandering over time, in addition to greater severity of cognitive impairment, discomfort or unsettled states (sad/pained expression, repetitive questioning), medication use (antipsychotics), constipation, and pneumonia.

The VA system is one of the largest healthcare systems in the world. It serves an aging veteran population with an increasing prevalence of dementia and chronic diseases associated with enhanced use of long-term care service. ${ }^{25,26}$ Little information is available on the nature and extent of wandering in older veterans, an almost exclusively male population. There is evidence that older men in the VA system differ on some demographic and medical variables from older men in community-based NHs. One study ${ }^{27}$ compared admission MDS assessments for 7,296 male VA $\mathrm{NH}$ residents with those of 159,203 men from community NHs. Significance testing revealed that veterans were slightly older (72 vs 71 ), more often divorced, racially more homogeneous, more independent in performing activities of daily living (ADLs) (less physically disabled), more likely to have comorbidities, and less likely to have received special treatments and procedures. It is unclear how such differences might cumulatively affect prevalence of wandering in veteran and nonveteran populations.

Given the lack of information on wandering behavior in male veteran $\mathrm{NH}$ residents, this study focused on identifying the prevalence and correlates of wanderers with cognitive impairment upon admission to VA NHs. The study analyzed MDS records obtained at $\mathrm{NH}$ admission over a 4-year period, comparing veterans identified on the MDS as wanderers with those who were nonwanderers. Based on a statistical model with variables generated from prior research findings, it was hypothesized that the classification of "wanderers" versus "nonwanderers" on the admission MDS would be associated with MDS-rated disruptive behavior problems.

\section{METHODS}

\section{Design}

A cross-sectional study was conducted using a retrospective review of MDS data obtained nationally from the VA for all assessments administered from October 15, 2000, through October 15, 2004. The University of South Florida and the VA national and local (James A. Haley VA Hospital) institutional review boards approved data use.

\section{Population}

The VA operates nursing home care units (NHCUs) at 134 medical centers across the United States and Puerto Rico. From 2000 through 2004, average daily census across all NHCUs ranged from 11,000 to more than 12,000 residents. ${ }^{28}$ As is the case for all NHs, NHCUs use the MDS for assessment purposes. During the years of this study, VA guidelines required admission assessments on all residents admitted for 14 days or more. Those residents with lengths of stay less than 14 days were customarily discharged without an MDS initial assessment and thereby were not necessarily available for inclusion in the study group.

\section{Measurement}

The MDS is the standard tool for assessing NH resident functioning required by the Centers for Medicaid and Medicare Services and is part of the mandatory Resident Assessment Instrument for all NHs in the United States. ${ }^{29}$ MDS items are completed within 7 days of $\mathrm{NH}$ admission and repeated quarterly thereafter and at discharge. Unusual 
events or changes in the resident's health conditions trigger additional assessments.

The MDS procedural manual describes wandering as "locomotion with no discernible, rational purpose" and differentiates wandering from purposeful movement. A related category of "pacing" (repetitive locomotion with no apparent goal) is not included in the "Behavioral Symptoms" section of the MDS, where wandering is defined, but is instead listed in the section entitled "Depression, Anxiety, and Sad Mood" and is listed as a subtype of "Repetitive Physical Movements." Wandering may be manifested as walking or locomoting in a wheelchair. This definition of wandering is consistent with other well-cited peer-reviewed papers. ${ }^{24}$

Within MDS Section E-4, all behavioral symptoms are rated on two criteria. The first, "symptom frequency in last 7 days" has four possible ratings: not exhibited, occurred 1 to 3 days, occurred 4 to 6 days but less than daily, and occurred daily. The second criterion is "symptom alterability in last 7 days," with a behavior rated as "not present or behavior as easily altered" or "not easily altered." For the present study, a NH resident was considered a wanderer based on the first criterion (symptom frequency $>0$ in the last 7 days). The resident was classified as a nonwanderer if the behavior was not exhibited.

\section{Inclusion and Exclusion Criteria}

To compare nonwanderers with wanderers, admission MDS assessments were identified, and based on these assessments, six inclusion criteria were used to specify cases to be included in the analyses:

Residents were first-time $\mathrm{NH}$ admissions; individuals were excluded if a previous stay in any type $\mathrm{NH}$ was noted on the MDS.

Residents were male; female residents constituted fewer than $2 \%$ of the cases and were excluded; a complete MDS admission assessment (complete basic demographics and key wandering variables in MDS Section E "Mood and Behavior Patterns") was available.

Residents were not in a comatose state.

Residents could ambulate freely with or without the aid of an assistive device or wheelchair.

Residents were classified on the MDS as having moderate or severe cognitive impairment based on the Cognitive Performance Scale (CPS). ${ }^{30}$

The CPS is made up of five MDS items reflecting mental status, short and long-term memory function, daily decision making, and an ADL eating item; CPS scores ranged from 0 (intact) to 6 (very severe cognitive impairment). Preliminary analysis revealed that $9.5 \%$ of wanderers $(\mathrm{n}=342)$ were rated as having no or only mild cognitive impairment, compared with $76 \%$ of nonwanderers with no or only mild cognitive impairment. This disproportion between wanderers and nonwanderers with no or mild cognitive impairment could result in inflated coefficients and complex three- or four-way interactions between the model variables. The group of wanderers with no or mild cognitive impairment also included a number of residents with psychiatric diagnoses and diverse neurological conditions. A major goal of this research was to formulate a model that discriminates wanderers from nonwanderers. To accomplish this goal, the analyses were restricted to residents with moderate to severe cognitive impairment $(\mathrm{n}=15,092)$. Those with no to mild cognitive impairment $(\mathrm{n}=38,401)$ were excluded from the procedure.

\section{Procedure and Analyses}

Relying on the inclusion and exclusion criteria, a sample of 15,092 unique cases was obtained. Table 1 provides the basic demographic description of the sample.

\section{Comparisons of Wanderers and Nonwanderers}

To explore characteristics of wanderers, candidate variables were identified from prior wandering research conducted in NHs. ${ }^{24}$ The overall factors include single-item and composite variables:

The cognitive factors included the CPS, described above, which was initially collapsed into three categories (none/mild, moderate, and severe), although as indicated above, only the two more-impaired categories (moderate and severe) were used in these analyses. Other MDS items included with the cognitive factors were easily distracted, altered perception, disorganized speech, mental function varies, and delirium. These items from the MDS were all

Table 1. Descriptive Characteristics for All Eligible Subjects $(\mathrm{N}=15,092)$

\begin{tabular}{|c|c|}
\hline Characteristic & Outcome \\
\hline Age, median (interquartile range) & $77(12)$ \\
\hline \multicolumn{2}{|l|}{ Marital status, n (\%) } \\
\hline Never married & $1,763(11.7)$ \\
\hline Married & $7,402(49.1)$ \\
\hline Widowed & $2,603(17.3)$ \\
\hline Separated & $387(2.6)$ \\
\hline Divorced & $2,931(19.4)$ \\
\hline Missing data & $3(0.02)$ \\
\hline \multicolumn{2}{|l|}{ Education, n (\%) } \\
\hline No schooling & $41(0.27)$ \\
\hline 8th grade or less & $2,118(14.0)$ \\
\hline $9-11$ grades & $2,377(15.8)$ \\
\hline High school & $6,598(43.7)$ \\
\hline Technical or trade school & $696(4.6)$ \\
\hline Some college & $1,728(11.5)$ \\
\hline Bachelor's degree & $887(6.0)$ \\
\hline Graduate degree & $405(2.7)$ \\
\hline Missing data & $240(1.6)$ \\
\hline \multicolumn{2}{|l|}{ Race/ethnicity, n (\%) } \\
\hline American Indian/Alaskan Native & $54(0.4)$ \\
\hline Asian/Pacific Islander & $69(0.5)$ \\
\hline Black (not Hispanic) & $1,791(11.9)$ \\
\hline Hispanic & $566(3.8)$ \\
\hline White (not Hispanic) & $12,596(83.5)$ \\
\hline Missing data & $16(0.1)$ \\
\hline \multicolumn{2}{|l|}{ Wandering status, n (\%) } \\
\hline Nonwanderer & $11,935(79.1)$ \\
\hline Wanderer & $3,157(20.9)$ \\
\hline \multicolumn{2}{|l|}{ Cognitive impairment, n (\%) } \\
\hline Moderate & $11,573(76.7)$ \\
\hline Severe & 3,519 (23.3) \\
\hline
\end{tabular}


dichotomized as 0 (behavior did not occur) or 1 (behavior occurred).

The behavior and mood factor "depression, mood and anxiety" composite measure was assembled from 15 items taken from MDS section E, sampling negative affect, repetitive movements, questions and verbalizations, and withdrawal from social situations. Scores ranged from 0 (no items observed in past 7 days) to 15 (all items observed). Other items associated with the behavior and mood factor were verbally abusive behavior, physically abusive behavior, socially inappropriate behavior, resists care, restlessness, and lethargy. As above, these items were dichotomized (behavior did/did not occur).

Physical factors included two ADL items (locomotion on unit and personal hygiene) that were categorized as independent (0), supervision or limited assistance (1), or extensive assistance or dependent (2).

Finally, the disease/medication factor consisted of an "ambulation" composite of 10 items in MDS section I that described residents with physical impediments to wandering (e.g., missing limb, hip fracture). Scores on this item were the summation of the number of impediments present. The second measure, use of antipsychotic medication, was determined from an item from MDS section $\mathrm{O}$ and dichotomized as 0 (no antipsychotic use in past 7 days) or 1 (antipsychotic use in previous 7 days).

\section{Statistical Analysis}

Initial relationships between $\mathrm{NH}$ resident characteristics and moderate to severe cognitive impairment were examined using separate bivariate logistic regression analysis to assess the strength of association between the discriminating variables for those who wander and those who do not. A multivariate logistic regression model was then developed including those factors found to be significant $(P<.05)$ in the bivariate analyses. To validate the results, a randomly selected training data set was used to develop the model, and then the model was tested on the remaining $60 \%$ of the data. In addition, model accuracy was tested using the receiver operating characteristic curve, which allows the discriminating ability of the model to be estimated.

\section{RESULTS}

In the study sample of 15,092 VA residents with moderate or severe cognitive impairment, 3,157 (21\%) were deemed wanderers on admission to the NHCU. Of these, $63 \%$ of wanderers were classified as having moderate cognitive impairment and $37 \%$ severe cognitive impairment, compared with $80 \%$ and $20 \%$ of the nonwanderers, respectively. Seventy-four and one-half percent of wanderers, compared with $39.5 \%$ of nonwanderers had dementia or Alzheimer's disease. Twenty-four percent of wanderers used wheelchairs, and $23 \%$ of wanderers had diagnoses of both dementia and a psychiatric condition.

Table 2 provides detailed descriptive characteristics of wanderers and nonwanderers. The only variables that did not differ significantly between wanderers and nonwanderers were medical variables, transient ischemic attack, bipolar disorder, and anxiety. Significant differences were seen in all other variables, and these included greater propor- tions of wanderers exhibiting signs of socially inappropriate behaviors, resisting care, and having altered perceptions.

As shown by the adjusted odds ratios in Table 3, behavior problems in general are often associated with wanderers. Increased chance of being classified as a wanderer on admission is associated with severe cognitive impairment based on the CPS score (2.33 greater odds, $95 \%$ confidence interval $(\mathrm{CI})=1.95-2.78$ vs moderate impairment), socially inappropriate behaviors (2.31 greater odds, 95\% $\mathrm{CI}=1.85-2.88)$, and resisting care $(2.05 \%$ greater odds, $95 \% \mathrm{CI}=1.69-2.50)$.

There are significant relationships between classification as a wanderer and moderate or severe cognitive impairment upon admission and the variables related to locomotion or ambulation; as expected, problems or physical conditions that restrict locomotion or ambulation reduce the likelihood of being categorized as a wanderer. Locomotion assistance on the unit was associated with less chance of being labeled a wanderer $(0.52$ lower odds, $95 \%$ $\mathrm{CI}=0.44-0.62)$ than for those requiring no assistance. Those completely dependent on others for locomotion assistance had $0.08(95 \% \mathrm{CI}=0.06-0.10)$ lower odds. For residents with a medical or physical condition limiting their ability to ambulate, odds of being classified as a wanderer were $0.56(95 \% \mathrm{CI}=0.46-0.67)$ lower than for those with no infirmity.

Residents who wandered were more likely to be deficient or dependent in certain ADLs. Those requiring limited assistance with personal hygiene had 2.06 (95\% CI $=1.61$ 2.65) lower odds of being classified as a wanderer than those requiring no assistance, whereas those who were dependent had 2.36 (95\% CI $=1.78-3.14)$ greater odds.

Other significant variables included in the multivariate logistic regression model included age and a depression, mood, and anxiety composite, although a one-unit change in age related to only $1.01(95 \% \mathrm{CI}=1.01-1.03)$ greater odds of being classified as a wanderer, and a one-unit change in the depression, mood, and anxiety composite score related to $1.06(95 \% \mathrm{CI}=1.02-1.10)$ greater odds of being classified as a wanderer.

The Hosmer-Lemeshow goodness-of-fit statistic was not significant (chi-square $=6.08$, degrees of freedom $=8$; $P=.64)$, suggesting that the model fits the data well. To assess collinearity, the tolerance and variance inflation factors were assessed and found to be in the normal range. The area under the receiver operating characteristic curve for the training data had a value of 0.815 , which suggests that the model fits the data well. The area under the curve for the test data had a value of 0.820 , which differs by only 0.005 , suggesting that the training model approximates the test data. In normal logistic regression, the cutoff is normally set to 0.5 , although because of a smaller number of wanderers, this cutoff point was reset to 0.21 . Given this cutoff, the sensitivity and specificity of the model were $73 \%$ and $75 \%$, respectively, with $74 \%$ of residents correctly classified.

\section{DISCUSSION}

This is the first large database study exclusively focusing on male residents with moderate or severe cognitive impairment who wander at admission to the nursing home, with statistical analyses validating a multivariate logistic regres- 
Table 2. Comparison of Wanderers and Nonwanderers

\begin{tabular}{|c|c|c|}
\hline Characteristic & $\begin{array}{c}\text { Nonwanderers } \\
(n=11,935)\end{array}$ & $\begin{array}{l}\text { Wanderers } \\
(n=3,157)\end{array}$ \\
\hline \multicolumn{3}{|l|}{ Cognitive factors, n (\%) } \\
\hline Altered perception & $2,972(24.90)$ & $1,480(46.88)^{\ddagger}$ \\
\hline Disorganized speech & $1,942(16.27)$ & $1,000(31.68)^{\ddagger}$ \\
\hline Mental function varies & $3,334(27.93)$ & $1,361(43.11)^{\ddagger}$ \\
\hline \multicolumn{3}{|l|}{ Behavior/mood factors } \\
\hline $\begin{array}{l}\text { Depression, mood, anxiety composite, } \\
\text { mean } \pm \text { standard deviation }\end{array}$ & $1.19 \pm 1.97$ & $2.21 \pm 2.68^{\ddagger}$ \\
\hline Verbally abusive behavior, n (\%) & $729(6.11)$ & $624(19.77)^{\ddagger}$ \\
\hline Physically abusive behavior, n (\%) & $414(3.47)$ & $478(15.14)^{\ddagger}$ \\
\hline Socially inappropriate/disruptive behavior, n (\%) & $791(6.63)$ & $810(25.66)^{\ddagger}$ \\
\hline \multicolumn{3}{|l|}{ Locomotion on unit } \\
\hline Independent & $3,789(31.75)$ & $1,723(54.58)$ \\
\hline Limited assistance & $3,864(32.38)$ & $1,120(35.48)$ \\
\hline Dependent & $4,282(35.88)$ & $314(9.95)^{\ddagger}$ \\
\hline \multicolumn{3}{|l|}{ Personal hygiene } \\
\hline Independent & $1,627(13.63)$ & $255(8.08)$ \\
\hline Limited assistance & $4,826(40.44)$ & $1,571(49.76)$ \\
\hline Dependent & $5,482(45.93)$ & $1,331(42.16)^{\ddagger}$ \\
\hline Ambulation & $4,249(35.60)$ & $561(17.77)^{\ddagger}$ \\
\hline \multicolumn{3}{|l|}{ Disease/medication factors, $\mathrm{n}(\%)$} \\
\hline Dementia/Alzheimer's disease & $2,353(74.50)$ & $4,721(39.50)^{\ddagger}$ \\
\hline Antipsychotic medication & $3,168(26.54)$ & $1,590(50.36)^{\ddagger}$ \\
\hline
\end{tabular}

$P<{ }^{*} .05,{ }^{\dagger} .01,{ }^{\ddagger} .001$.

sion model used to classify wanderers and nonwanderers. The main finding that wanderers exhibit more-severe cognitive symptoms is consistent with previous studies, ${ }^{9,16}$ although the prevalence of male residents who wander in VA NHs $(21 \%)$ based on MDS admission ratings was found to be higher than the prevalence reported for non-VA male $\mathrm{NH}$ residents based on MDS admission ratings in previous studies $\left(11 \%^{24}\right.$ and $\left.1 \%{ }^{23}\right)$. Given that wanderers exhibit more-severe cognitive symptoms, the greater percentage of wanderers in the current study could be due to its including only those with moderate to severe cognitive impairment, because one of the previous studies ${ }^{24}$ included all $\mathrm{NH}$ residents with or without severe cognitive impairment, and the other study ${ }^{23}$ included residents with Alzheimer's disease with mild impairment. In contrast, the estimate in the current study was in the low range compared with the wandering prevalence rates of other studies sampling individuals diagnosed with dementia, as reported in a comprehensive literature review. ${ }^{16}$ It could be that the one wandering item on the MDS detects only more-observable or -frequent wandering behavior than other studies that use more-sensitive and thorough instruments geared toward behavior problems, thereby yielding higher estimates.

As was hypothesized, consistent with the findings of the previous study, ${ }^{23}$ being classified as a wanderer was found to be associated with other disruptive activity such as socially inappropriate behavior and resisting care. The results also show that a substantial proportion of wanderers use wheelchairs $(24 \%)$, a finding that has not been well documented in the literature. The study also revealed large numbers of residents with dual diagnoses of dementia and psychiatric illness (23\%).

Categorization as a wanderer appears to be integrally linked with better physical capacity for mobility. Although mobility is a prerequisite for wandering, caregivers may not recognize that wandering can occur when residents use alternative modes of mobility, including assistive devices (e.g., walker or cane) or wheelchairs (propelled forward or backward). "Wheelchair wandering" is a relatively understudied concept, and this nontraditional method of ambu- 
Table 3. Multivariate Logistic Regression Model

\begin{tabular}{|c|c|c|c|c|c|}
\hline Independent Variable & Odds Ratio & $\begin{array}{l}\text { Adjusted } \\
\text { Odds Ratio }\end{array}$ & $\begin{array}{l}\text { Standard } \\
\text { Error }\end{array}$ & $P$-value & $\begin{array}{l}\text { 95\% Confidence } \\
\text { Interval }\end{array}$ \\
\hline Cognitive Performance Scale* & 2.40 & 2.33 & 0.21 & $<.001$ & $1.95-2.78$ \\
\hline Age & 1.01 & 1.02 & 0.01 & $<.001$ & $1.01-1.03$ \\
\hline Depression, mood, anxiety composite & 1.21 & 1.06 & 0.02 & .001 & $1.02-1.10$ \\
\hline Socially inappropriate behavior & 4.88 & 2.31 & 0.26 & $<.001$ & $1.85-2.88$ \\
\hline Resists care & 3.76 & 2.05 & 0.20 & $<.001$ & $1.69-2.50$ \\
\hline \multicolumn{6}{|l|}{ Locomotion on unit } \\
\hline No assistance & Reference & & & & \\
\hline Limited assistance & 0.66 & 0.52 & 0.04 & $<.001$ & $0.44-0.62$ \\
\hline Dependent & 0.16 & 0.08 & 0.01 & $<.001$ & $0.06-0.10$ \\
\hline \multicolumn{6}{|l|}{ Personal hygiene } \\
\hline No assistance & Reference & & & & \\
\hline Limited assistance & 2.15 & 2.06 & 0.26 & $<.001$ & $1.61-2.65$ \\
\hline Dependent & 1.50 & 2.36 & 0.34 & $<.001$ & $1.78-3.14$ \\
\hline Ability to ambulate & 0.33 & 0.56 & 0.05 & $<.001$ & $0.47-0.67$ \\
\hline Use of antipsychotic medication & 2.64 & 1.47 & 0.11 & $<.001$ & $1.27-1.72$ \\
\hline Easily distracted & 3.17 & 2.15 & 0.17 & $<.001$ & $1.84-2.51$ \\
\hline
\end{tabular}

Note: Estimates taken from the training analyses $(n=6,056)$.

* The reference group for this comparison is the moderate cognitive impairment group.

lation may thereby cause some $\mathrm{NH}$ staff care providers to be less attentive to wandering behavior with these residents when completing assessments. Insights from clinical researchers with dual experience with wanderers and wheelchair behavior will be critical in describing, measuring, and treating inappropriate wheelchair wandering behaviors.

Despite the fact that wanderers are typically more independent in locomotion or ambulation than nonwanderers, they are more dependent in their hygienic ADLs. This contrast between certain types of dependency behaviors is a striking feature and may serve as a simple guide for $\mathrm{NH}$ or hospital admission coordinators to target potential wanderers. It is hoped that this statistical model can continue to be refined so that algorithms can be generated to accurately identify those who are at greatest risk for wandering.

Consistent with the previous study, ${ }^{24}$ use of antipsychotic medication was also associated with greater chance of being classified as a wanderer, which in turn may be related to the other study's ${ }^{23}$ finding that antipsychotic medications are more likely to be administered to men with Alzheimer's disease exhibiting behavior problems. It therefore will be important for applied researchers to determine the cause-and-effect nature of the relationship between current antipsychotic usage and wandering. That is, does wandering behavior trigger prescription of antipsychotic medication, or are antipsychotics used for the management of other behavior problems for residents with dementia, neurological syndromes, and psychiatric diagnoses, thereby precipitating iatrogenic wandering behavior? Do similar findings hold for men and women? Such research will have immediate practical treatment implications.

Residents with dual diagnoses of dementia and a major mental disorder such as depression, anxiety, or schizophrenia exhibit wandering in noteworthy numbers, enough for clinical staff to be trained to evaluate possible diverse causes of wandering in this sizable group. Although the wandering associated with dementia alone may differ in etiology from the wandering of residents with dementia and comorbid psychiatric problems, clinicians rate the features and implications of the behavior similarly on the MDS. Practitioners therefore may expect to encounter certain well-described challenges in caring for wandering residents, regardless of comorbid conditions. Alternatively, this understanding broadens clinical thinking about less-typical behaviors that a NH resident might exhibit. For example, such awareness would be important in the case of the significant number (more than one-fifth) of wanderers with comorbid depression whose wandering is inconsistent with the traditional presentation of psychomotor retardation for those with depression. Clinical evaluation also becomes important to distinguish, to the extent possible with current assessment strategies, wandering from similar behavioral problems such as anxiety, agitation due to depression, hypomania, and medication-related mobility disorders (e.g., akathisia). Clinicians with limited knowledge of wandering and other mobility disorders associated with neuroleptic side effects may be rating residents as wanderers when instead they have akathisia, affective instability, or general restlessness due to diverse neurological or psychiatric conditions. Appropriate early attention to wandering risk, with management plans earmarked for behavioral problems rather than medical diagnosis, is necessary. Strategies that potentially mitigate wandering in one diagnostic group may require adjustment to be effective in other diagnostic groups.

A growing body of literature indicates that use of physical and chemical restraints to prevent unsafe wandering is not good clinical practice. Overall, programs implemented to reduce use of physical restraints have not resulted in greater harm or injury to residents. ${ }^{31}$ Although a number of environmental modifications and social programs to reduce problematic wandering have been developed and evaluated, much more intervention research needs to be conducted with this population. ${ }^{31}$ Interventions that have 
been successfully implemented in long-term care settings include a meal-time communication strategy designed to help people sit longer during mealtimes; ${ }^{32,33}$ behavior modification procedures for use by long-term care staff (unpublished data); an early-evening walking program for residents with severe dementia; ${ }^{34}$ and use of multisensory stimuli, exercise, or aroma therapy to reduce wandering. ${ }^{35}$ Research examining the effects of physical changes to the facility (night lights, modifying exits with covered doorknobs and locks, warning bells, monitoring devices, and enhanced facility environment) demonstrates that physical environmental factors can facilitate or inhibit wandering and play a role in management of wandering. ${ }^{36,37}$ Resident preferences and personality should be considered when selecting interventions to address wandering. Use of interventions such as behavior modification techniques, environmental alterations, and social therapeutic activities may help create a safe and pleasant environment for staff and residents and deliver meaningful programming to people with dementia who wander.

Nevertheless, although wanderers present challenges to care providers, not all wandering should be deemed problematic. Wandering has been described as therapeutic and health-inducing, in the sense that the resident keeps active and gets exercise while aimlessly and repetitively moving around the $\mathrm{NH}$ unit. ${ }^{37,38}$ Indeed, environmental adaptations to encourage therapeutic wandering and to reduce problematic wandering have been developed and evaluated, ${ }^{39}$ although sensitivity to fatigue and the necessity for rest and hydration in residents who cannot control excessive mobility must temper such a positive outlook. This is particularly important for residents who may be unable to communicate needs well (e.g., those with dementia) and for those who use upper body strength and additional energy to propel a wheelchair. Perhaps it is most important to recognize that wandering behavior comes in a variety of forms and etiologies serving multiple goals and yielding diverse outcomes.

The data were limited to elements included in the MDS. Although high interrater reliability of nurse-pair ratings of MDS behaviors, including wandering, has been demonstrated, ${ }^{40}$ some observers have questioned the overall reliability and validity of the MDS. ${ }^{41}$ The MDS items are rated on a particular assessment day covering the previous 1 -week period, and the MDS wandering variable responses were categorized into those who wander and those who do not. Dichotomizing the wandering variable and not recording the frequency of wandering within each day restricted the analysis of the frequency, variation, and types of wandering.

Further studies using specialized in-depth non-MDS assessment instruments are needed to examine more intensively the links between frequency, types, and duration of wandering (e.g., Algase Wandering Scale ${ }^{42}$ ), psychiatric symptomatology (e.g., Brief Psychiatric Rating Scale ${ }^{43}$ ), other inappropriate behaviors (e.g., Cohen Mansfield Agitation Inventory $\left.{ }^{44}\right)$, and cognitive status (e.g., Cognistat $\left.{ }^{45}\right)$. Additional research investigating different types of wandering is warranted to determine optimal assessment and treatment strategies for subgroups of problematic wanderers who are unable to ambulate, who move in nontraditional ways (e.g., in wheelchairs), who exhibit minor cognitive impairment, or who share multiple comorbidities. Sex prevalence estimates, premorbid history, mobility patterns, quality-of-life indices, and environmental context need to be further explored. As noted above, not all wandering is problematic, and researchers should examine how to educate caregivers about promoting environments that are conducive to gainful exercise and nonhazardous physical activity. To initiate preventative efforts when wandering is deemed problematic, there is a compelling need to conduct longitudinal investigations to refine predictive models for the identification of residents who develop wandering over time. Studies are greatly needed that will generate the development of a user-friendly algorithm that employs a simple standardized wandering assessment to allow family members or nursing staff to implement specific wandering protocols based on the unique bio-psycho-social circumstances of the individual and to mitigate the particular problem caused by the wandering behavior.

\section{ACKNOWLEDGMENTS}

The authors would like to express their sincere appreciation to all the members of the International Wandering Consortium for their contributions to this paper. We would also like to thank the Department of Veterans Affairs for allowing us access to the data analyzed in this study.

Financial Disclosure: None-this was an unfunded project.

Author Contributions: Lawrence Schonfeld, Elizabeth R. Beattie, and Audrey L. Nelson: design, analysis and interpretation, manuscript preparation. Bellinda King-Kallimanis: analysis and interpretation, manuscript preparation. Lisa M. Brown and Victor Molinari: design, manuscript preparation. Darlene M. Davis: design, data acquisition. William D. Kearns: design, analysis and interpretation. Dennis H. Weaver: design, data acquisition, analysis and interpretation.

Sponsor's Role: None-this was an unsponsored project.

\section{REFERENCES}

1. Algase DL. Wandering. In: Edelstein B, ed. Comprehensive Clinical Psychology, Vol. 7. London: Pergamon, 1998, pp 271-412.

2. Algase DL, Struble L. Wandering: What, why \& how? In: Buckwalter K, ed. Geriatric Mental Health Nursing. Current and Future Challenges. Thorofare, NJ: Slack, 1992, pp 61-74.

3. Cancro R. Elopements from the C.F. Menninger Memorial Hospital. Bull Menninger Clinic 1968;32:228-238.

4. Fompa-Loy J. Wandering: Causes, consequences, and care. J Psychosoc Nurs Ment Health Serv 1998;26:8-11, 15-18.

5. Rheaume Y, Riley ME, Volicer L. Meeting nutritional needs of Alzheimer's patients who pace constantly. J Nutr Elder 1987;7:3-52.

6. Soverini S, Borghesi E. On a strange case of wandering in an arteriosclerotic demented patient. Gerontology 1968;16:846-851.

7. Stokes G. Wandering, Common Problems with the Elderly Confused. Bicester, UK: Winslow Press, 1986.

8. Kiely DK, Kiel DP, Burrows AB et al. Identifying nursing home residents at risk for falling. J Am Geriatr Soc 1998;46:551-555.

9. Snyder LH, Rupprecht P, Pyrek J et al. Wandering. Gerontologist 1978;18: $272-280$.

10. Kopetz S, Steele CD, Brandt J et al. Characteristics and outcomes of dementia residents in an assisted living facility. Int J Geriatr Psychiatry 2000;15: 586-593

11. Moak GS. Characteristics of demented and nondemented geriatric admissions to a state hospital. Hosp Community Psychiatry 1990;41:799-801. 
12. Vieweg V, Blair CE, Tucker R et al. Factors precluding patients' discharge to the community: A geropsychiatric hospital survey. Va Med Q 1995;122: 275-278.

13. Cesari M, Landi F, Torre $S$ et al. Prevalence and risk factors for falls in an older community-dwelling population. J Gerontol A Biol Sci Med Sci 2002;57A: M722-M726.

14. Colombo M, Vitali S, Cairati $M$ et al. Wanderers: Features, findings, issues. Arch Gerontol Geriatr Suppl 2001;7:99-106.

15. Algase DL, Beel-Bates C, Beattie ER. Wandering in long-term care. Ann Long Term Care 2003;11:33-39.

16. Lai CK, Arthur DG. Wandering behavior in people with dementia. J Adv Nurs 2003;44:173-182.

17. Cooper JK, Mungas D. Risk factor and behavioral differences between vascular and Alzheimer's dementias: The pathway to end-stage disease. J Geriatr Psychiatry Neurol 1993;6:29-33.

18. Thomas DW. Understanding the wandering patient. A continuity of personality perspective. J Gerontol Nurs 1997;23:16-24.

19. Monsour N, Robb SS. Wandering behavior in old age: A psychosocial study. Soc Work 1982;27:411-416.

20. Sloane PD, Mitchell CM, Preisser JS et al. Environmental correlates of resident agitation in Alzheimer's disease special care units. J Am Geriatr Soc 1998;46: 862-869.

21. Hussian RA. Severe behavioral problems. In: Teri L, Lewinsohn P, eds. Geropsychological Assessment and Treatment. New York: Springer, 1986, pp 121-143.

22. Dawson P, Reid D. Behavioral dimensions of patients at risk of wandering. Gerontologist 1987;27:104-107.

23. Ott BR, Lapane KL, Gambassi G. Gender differences in the treatment of behavior problems in Alzheimer's disease. Neurology 2000;54:427-432.

24. Kiely DK, Morris JN, Algase DL. Resident characteristics associated with wandering in nursing homes. Int J Geriatr Psychiatry 2000;15:1013-1020.

25. Krishnam LL, Petersen NJ, Snow AL et al. Prevalence of dementia among Veterans Affairs medical care system users. Dement Geriatr Cogn Disord 2005;20:245-253.

26. Villa VM, Harada ND, Washington D et al. The health and functional status of U.S. veterans aged 65+: Implications for VA health programs serving an elderly, diverse veteran population. Am J Med Qual 2003;18:108-116.

27. Buchanan R, Johnson C, Wang S et al. Analyses of male residents in community nursing facilities: Comparisons of Veterans Health Administration residents to other residents. J Rehabil Res Dev 2004;41:847-860.

28. Office of the Assistant Deputy Under Secretary for Health. Veterans Affairs Site Tracking System Reports FY2001 and FY2004. Washington, DC: Department of Veterans Affairs, 2006.
29. Morris JN, Hawes C, Fries BE et al. Designing the national resident assessment instrument for nursing homes. Gerontologist 1990;30:293-307.

30. Morris JN, Fries BE, Mehr DR et al. MDS Cognitive Performance Scale. J Gerontol 1994;49:M174-M182.

31. Tilly J, Reed P, eds. Dementia Care Practice Recommendations for Assisted Living Residences and Nursing Homes Phase 2 Resident Wandering, Resident Falls and Physical Restraint Free Care, Alzheimer's Association, 2006 [on-line]. Available at www.alz.org/qualitycare Accessed January 5, 2007.

32. Beattie E, Algase DL. Improving table-sitting behaviour of wanderers via theoretical substruction: Designing an intervention. J Gerontol Nurs 2002; 28:6-11.

33. Beattie E, Algase DL, Song J. Keeping wandering nursing home residents at the table: improving food intake using a behavioural communication intervention. Aging Ment Health 2004;8:109-116.

34. Holmberg S. Evaluation of a clinical intervention for wanderers on a geriatric nursing unit. Arch Psychiatr Nurs 1997;11:21-28.

35. Robinson L, Hutchings D, Corner L et al. A systematic literature review of the effectiveness of non-pharmacological interventions to prevent wandering in dementia and evaluation of the ethical implications and acceptability of their use. Health Technol Assess 2006;10:1-124.

36. Cohen-Mansfield J, Werner P. The effects of an enhanced environment on nursing home residents who pace. Gerontologist 1998;38:199-208.

37. Yao L, Algase D. Environmental ambiance as a new window on wandering. Western J Nurs Res 2006;28:89-104.

38. Cohen-Mansfield J, Werner P, Marx MS et al. Two studies of pacing in the nursing home. J Gerontol 1991;46:M77-M83.

39. Cohen-Mansfield J, Werner P. Outdoor wandering parks for persons with dementia. A survey of characteristics and use. Alzheimer Dis Assoc Disord 1999;13:109-117.

40. Mor V, Angelelli J, Jones R et al. Inter-rater reliability of nursing home quality indicators in the U. S. BMC Health Serv Res 2003;3:20.

41. Arling G, Kane RL, Lewis T. Future development of nursing home quality indicators. Gerontologist 2000;45:147-156.

42. Algase DL, Beattie ER, Bogue EL et al. The Algase Wandering Scale. Initial psychometrics of a new caregiver reporting tool. Am J Alzheimers Dis Other Demen 2001;16:141-152.

43. Overall JE, Gorham DN. The Brief Psychiatric Rating Scale. Psychol Rep 1962;10:799-812.

44. Cohen-Mansfield J, Marx MS, Rosenthal AS. A description of agitation in a nursing home. J Gerontol 1989;44:M77-M84.

45. Kiernan RJ, Mueller W, Langston JW et al. The Neurobehavioral Cognitive Status Examination: A brief but quantitative approach to cognitive status. Ann Intern Med 1987;107:481-485. 